\title{
Outcomes of surgical management of buschke-lowenstein tumor in a Philippine tertiary hospital
}

\author{
Sofia Isabel T. Manlubatan, Mark Augustine S. Onglao, Mayou Martin T. Tampo, Marc Paul J. Lopez \\ Division of Colorectal Surgery, Philippine General Hospital, University of the Philippines Manila, Manila, Philippines
}

Buschke-Lowenstein tumor (BLT) is a sexually transmitted infection (STI) caused by the human papillomavirus. This study investigated the profile, management, and outcomes of patients who underwent surgery for BLT from 2015 to 2019 at the Philippine General Hospital. Seven patients underwent surgery for BLT. All were male, with ages ranging from 21 to 41 years. Presenting symptoms were anal mass, foul-smelling discharge, pain, bleeding, and pruritus. All were positive for human immunodeficiency virus. All admitted to having engaged in both insertive and receptive anal intercourse, with multiple partners. All underwent excision with healing by secondary intention. Two had recurrence of warts. Four had an anal stricture. Of these, 3 underwent anal dilatation, while 1 had to undergo proximal bowel diversion. One had intraepithelial carcinoma without dermal invasion on histopathologic analysis. BLT is a rare STI characterized by local aggressiveness but with low malignant potential. Wide excision remains to be the mainstay of treatment.

Keywords: Buschke-Lowenstein tumor; Giant condyloma acuminata; Papillomaviridae

\section{INTRODUCTION}

The Philippines, at present, has the fastest-growing number of cases of human immunodeficiency virus (HIV) in the world. Consequently, other sexually transmitted infections (STI) are rising in number as well. The majority of these patients are men having sex with men (MSM) in the 15 to 24 years old subgroup.

Buschke-Lowenstein tumor (BLT), or giant condyloma acuminata, is an STI caused by the human papillomavirus (HPV). It is a slow-growing, locally aggressive disease that presents as a verrucous plaque in the anogenital region. In the adult population, an estimated incidence of about $0.1 \%$ was reported. Though a relatively rare disease entity, the number of reported cases of BLT has increased in recent years.

This study discussed the clinical profile, management, and treat-

Received: Aug 27, 2020 - Revised: Oct 13, 2020 - Accepted: Nov 3, 2020 Correspondence to: Mark Augustine S. Onglao, M.D.

Division of Colorectal Surgery, Philippine General Hospital, University of the Philippines Manila, 670 Padre Faura St, Ermita, Manila 1101, Philippines

Tel: +63-9399148310, Fax: +63-85548400

E-mail:maconglao@gmail.com

ORCID: https://orcid.org/0000-0003-2175-9959

(C) 2022 The Korean Society of Coloproctology

This is an open-access article distributed under the terms of the Creative Commons Attribution NonCommercial License (https://creativecommons.org/licenses/by-nc/4.0) which permits unrestricted non-

commercial use, distribution, and reproduction in any medium, provided the original work is properly cited. ment outcomes of patients with BLT. The Research Ethics Board of University of the Philippines Manila approved this report (No. UPMREB 2021-0493-01) and a the patients' consents were waived by the Board as this report only included review of records and did not employ any new intervention. The privacy and anonymity of the patients included in the study were ensured. Code numbers were used for each patient, and all data collection forms were perused only by the authors. Data pertinent to the patients included in this series are summarized in Table 1.

\section{CASE REPORTS}

\section{Case 1}

A 33-year-old male with no known comorbidities nor previous surgery presented with a 2-year history of a gradually enlarging anal mass with associated pruritus, foul-smelling discharge, and occasional bleeding. He initially self-medicated with warm sitz bath prior to consult. He was positive for HIV and was on antiretroviral therapy for 2 years before his lesions occur. He admitted to practice heterosexual and homosexual intercourse with multiple partners. He was also involved in both receptive and insertive anal intercourse. On physical examination, there was note of an almost circumferential, fungating anal mass with minimal discharge, enlarged left inguinal lymph node, and multiple small pigmented condylomatous lesions on the base and shaft of the penis and 
Table 1. Patient profile, postoperative length of stay, complications, and histopathologic results of patients with Buschke-Lowenstein tumor from January 2015 to December 2019

\begin{tabular}{|c|c|c|c|c|c|c|c|}
\hline $\begin{array}{l}\text { Patient } \\
\text { No. }\end{array}$ & $\begin{array}{l}\text { Age }(y r) / \\
\text { sex }\end{array}$ & Comorbidity & $\begin{array}{l}\text { Onset of symptoms } \\
\text { to surgery (mo) }\end{array}$ & $\begin{array}{l}\text { Postoperative stay } \\
\text { (day) }\end{array}$ & $\begin{array}{l}\text { Postoperative } \\
\text { complication }\end{array}$ & $\begin{array}{l}\text { Histopathologic } \\
\text { result }\end{array}$ & $\begin{array}{c}\text { Time to } \\
\text { epithelialization (wk) }\end{array}$ \\
\hline 1 & 33/male & None & 48 & 11 & $\begin{array}{l}\text { Recurrence (2 mo), } \\
\text { stricture (2-11 mo) }\end{array}$ & Condyloma acuminata & 8 \\
\hline 2 & 33/male & $\begin{array}{l}\text { Idiopathic thrombocytic } \\
\text { purpura, smoking }\end{array}$ & 12 & 2 & Stricture (3 mo) & Condyloma acuminata & 4 \\
\hline 3 & 29/male & None & 8 & 1 & None & $\begin{array}{l}\text { Intraepithelial carcinoma } \\
\text { without dermal invasion }\end{array}$ & 4 \\
\hline 4 & 23/male & None & 8 & 1 & $\begin{array}{l}\text { Recurrence (8 mo), } \\
\text { stricture (2 wk) }\end{array}$ & Condyloma acuminata & 4 \\
\hline 5 & $21 /$ male & None & 5 & 2 & None & Condyloma acuminata & 2 \\
\hline 6 & 29/male & None & 8 & 2 & Stricture (2 mo) & Condyloma acuminata & 16 \\
\hline 7 & 41/male & None & 36 & 2 & None & Condyloma acuminata & 8 \\
\hline
\end{tabular}

around the scrotum. He underwent left inguinal lymph node biopsy and excision of genital and perianal warts. He stayed for 11 days postoperatively. At 2 months postoperatively, the wound was noted to be completely epithelialized; however, there was also note of recurrence and stricture. The recurrence was addressed by cauterization and the stricture by anal dilatation. However, at 11 months postoperatively, there was further progression of the stricture warranting a proximal bowel diversion. Anoplasty was not done on this patient as he has been lost to follow up.

\section{Case 2}

Another 33-year-old male diagnosed with idiopathic thrombocytic purpura, a 5-pack year smoker, and with no previous surgery presented with a 1-year history of gradually enlarging anal mass. It is associated with foul-smelling discharge, pain, and occasional bleeding. He self-medicated with an unrecalled topical agent prior to consultation. He admitted to engage on homosexual, receptive and insertive anal intercourse with 6 partners. He was tested for HIV, which turned out positive. On physical examination, there was note of a large, circumferential perianal wart, and multiple subcentimeter scrotal and penile shaft warts. He underwent excision of the mass and stayed for 2 days postoperatively (Fig. 1). Complete epithelialization was noted at 4 weeks. However, at 3 months postoperatively, there was note of anal stricture, which was addressed by serial anal dilatation. No other recurrence and complications were noted up to 2 years of follow-up.

\section{Case 3}

A 29-year-old male, positive for HIV and on antiretroviral therapy, presented with an 8-month history of multiple fungating anal lesions. This was associated with foul-smelling discharge, occasional pain, and occasional bleeding. He engaged in homosexual, receptive and insertive anal intercourse with multiple partners.
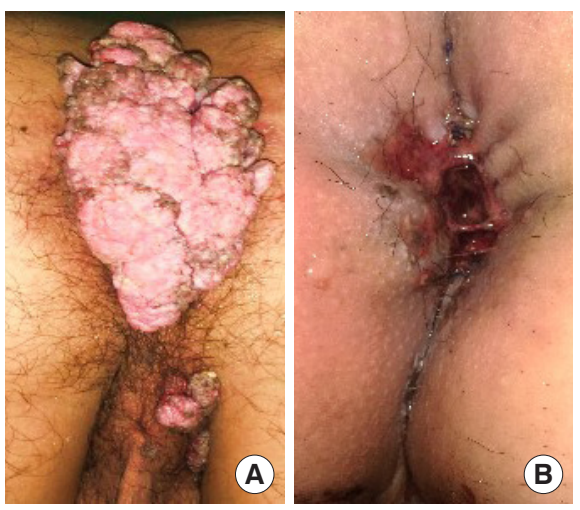

Fig. 1. (A) Preoperative and (B) postoperative photos of a 33-yearold male with Buschke-Lowenstein tumor who underwent excision of the mass. Philippine General Hospital, 2017.

On physical examination, there were several cauliflower-like lesions at the anal verge. He underwent excision of the lesions and was discharged immediately. Complete epithelialization was noted at 4 weeks postoperatively, with no note of recurrence or stricture on follow-up.

\section{Case 4}

A 23-year-old male, positive for HIV and on antiretroviral therapy since 2 years prior to consult, came in for an 8-month history of an enlarging anal mass. It is associated with pruritus, pain, and foul-smelling discharge. He self-medicated by applying apple cider vinegar, with no note of resolution nor improvement. He practiced homosexual, receptive and insertive anal intercourse with 10 partners. On physical examination, there was a circumferential, fungating mass at the anal verge. He underwent excision of the mass and was discharged immediately after. At 2 weeks 


\section{Coloproctology $\begin{array}{r}\text { Annals of } \\ \text { Outcomes of surgical management isabel T. Manlubatan, et al. }\end{array}$}
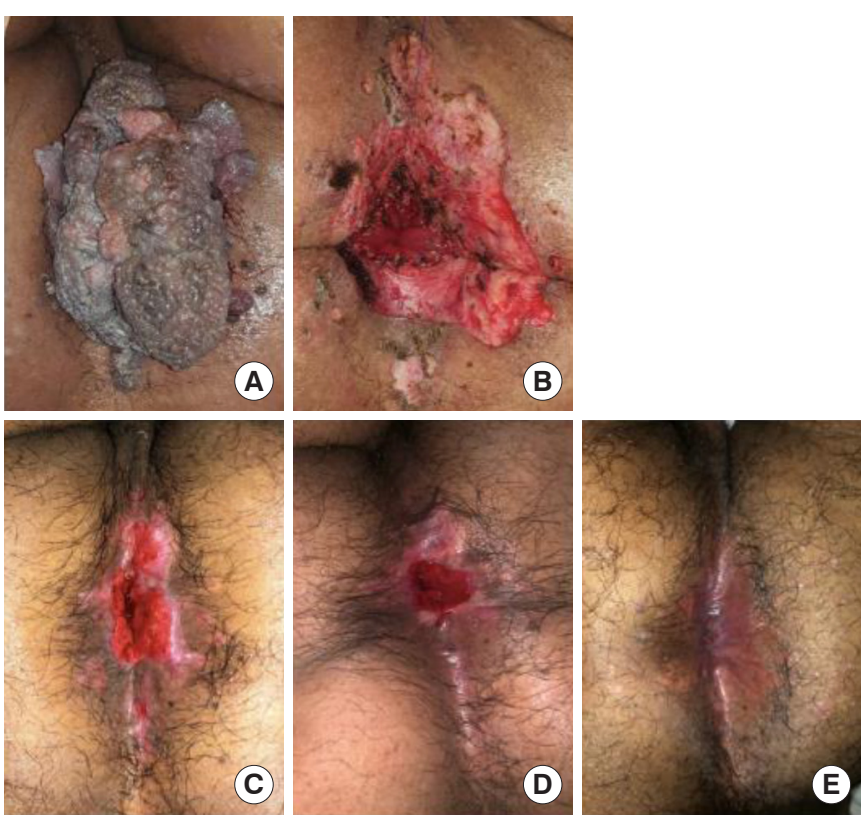

Fig. 2. (A) Preoperative, (B) immediate postoperative, (C) 2-week postoperative, (D) 8-week postoperative, and (E) 17-week postoperative photos of a 29-year-old male with Buschke-Lowenstein tumor who underwent excision. Philippine General Hospital, 2019.

postoperatively, during the course of the epithelialization process, there was note of a stricture. This was managed with anal dilatation. Complete epithelialization was noted at 4 weeks, but there was note of subcentimeter recurrence at 8 months postoperatively. This was then addressed with cauterization. No recurrence or other complications were noted up to 15 months postoperatively.

\section{Case 5}

A 21-year-old male with no comorbidities nor previous surgery consulted for a 5-month history of an anal mass with occasional bleeding, pain, and foul-smelling discharge. HIV testing was done which turned out positive. He was immediately started on antiretroviral therapy. On physical examination, there was a $15 \times 10-\mathrm{cm}$ fungating mass extending up to the dentate line. He underwent flexible sigmoidoscopy, endoanal ultrasonography, and excision of the mass. He was discharged after 2 days. Epithelialization was reported at 2 weeks postoperatively. No complications were noted up to 8 months postoperatively.

\section{Case 6}

A 29-year-old male, on antiretroviral therapy for HIV since 2 years prior to consult, presented with an 8-month history of perianal mass, with associated pain, bleeding, and foul-smelling discharge. He admitted to practice homosexual practice with more than 10 partners. On physical examination, there was a large circumferential perianal mass with multiple lesions at the genital area. He underwent excision of the perianal mass and cauteriza-
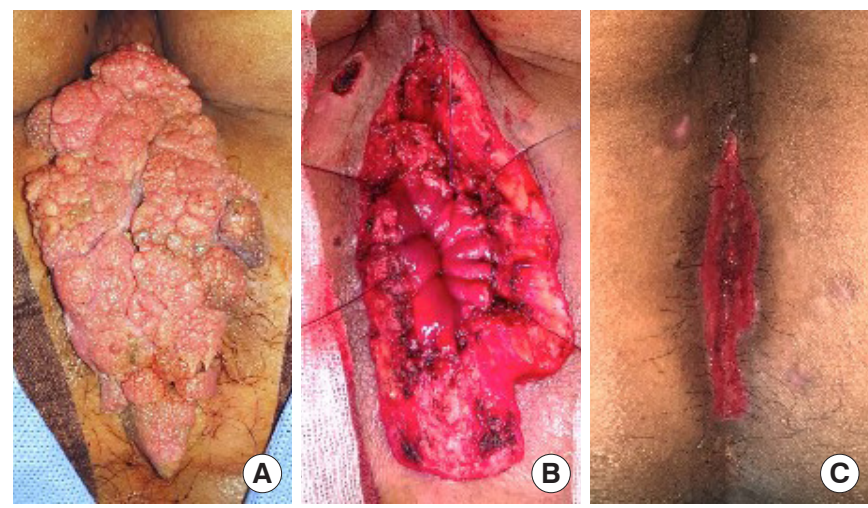

Fig. 3. (A) Preoperative, (B) immediate postoperative, and (C) 3-week postoperative photos of a 41-year-old male with BuschkeLowenstein tumor who underwent excision of the mass. Philippine General Hospital, 2019.

tion of the smaller lesions. He was discharged after 2 days. There was note of stricture formation at 2 months postoperatively managed by anal dilatation. Epithelialization was noted 16 weeks postoperatively. No other complications were noted (Fig. 2).

\section{Case 7}

A 41-year-old male, HIV-positive for 4 years, presented with a 3-year history of slow-growing perianal mass with foul-smelling discharge and pruritus. He self-medicated with an unrecalled cream with no note of improvement. He practiced both heterosexual and homosexual intercourse with multiple partners. On physical examination, there was note of a circumferential, confluent fleshy outgrowth at perianal area with intraanal component and smaller lesions at the gluteal areas. He underwent excision of the lesions and was sent home after 2 days. Complete epithelialization was noted at 8 weeks. No complications were noted up to 5 months postoperatively (Fig. 3).

\section{Summary of cases}

A total of 7 patients underwent surgery for BLT. All were male with ages ranging from 21 to 41 years (median, 29 years). All presented for consult with the chief complaint of an anal mass (i.e., cauliflower-like lesion). Other reported signs and symptoms were foul-smelling discharge (100\%, 7 of 7), pain ( $71.4 \%, 5$ of 7), bleeding $(71.4 \%, 5$ of 7$)$, and pruritus (28.6\%, 2 of 7). Duration from the initial discovery of an anal lesion to time of consult ranged from 5 months to 4 years (median, 8 months). Seventy-one percent of the respondents self-medicated with various topical agents and home remedies (i.e., apple cider vinegar) prior to consult with a physician. These were on the recommendation of persons with no medical background.

All the patients were HIV-positive and were already receiving antiretroviral therapy at the time of initial consult. All were involved in MSM, with multiple partners. Two also engaged in het- 

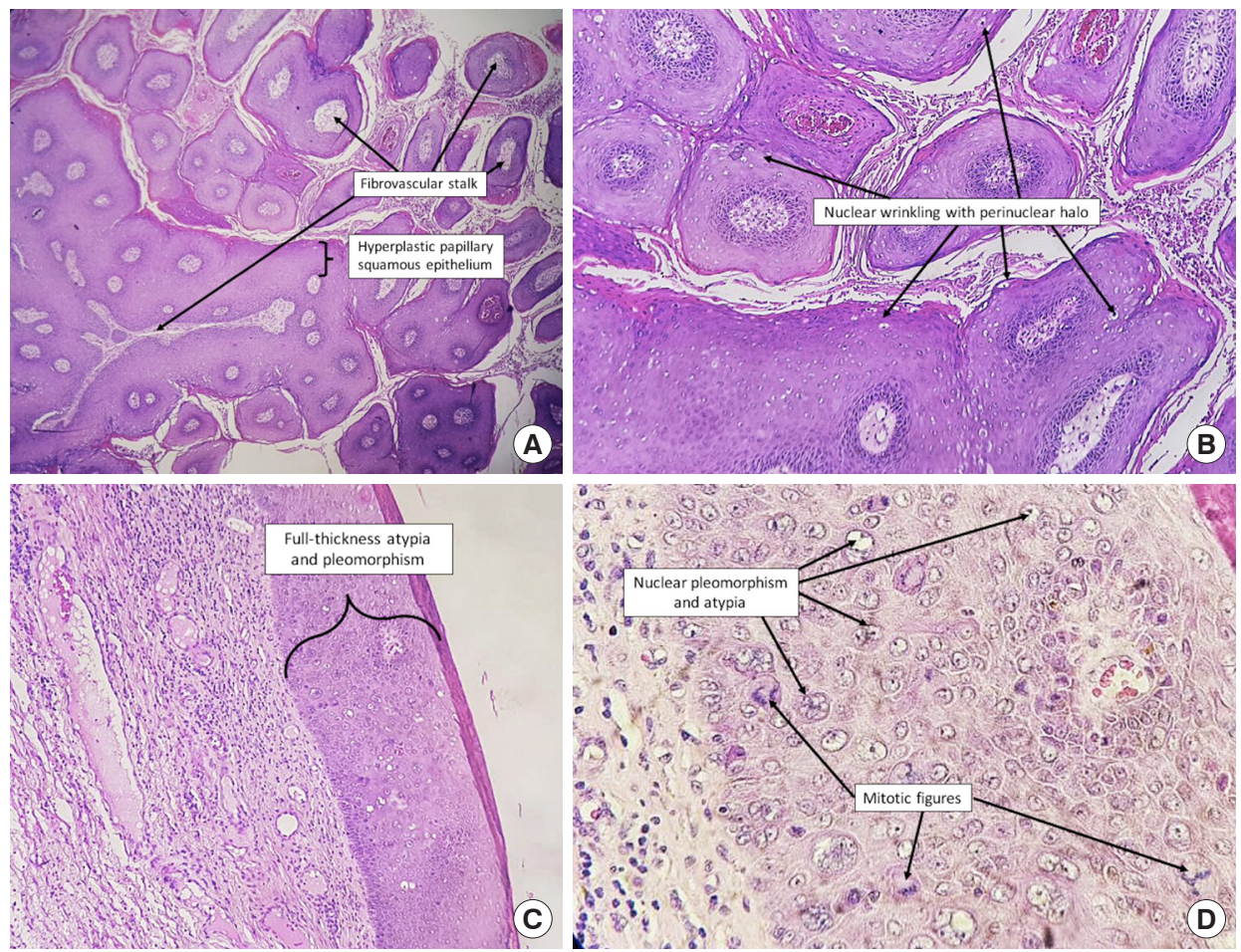

Fig. 4. Histopathologic features of intraepithelial carcinoma. (A) Scanning view of condylomata acuminata showing hyperplastic papillary squamous epithelium with parakeratosis, variable koilocytotic atypia (nuclear wrinkling with perinuclear clearing) (H\&E, $\times 40)$. (B) Low power view of the variable koilocytotic atypia (nuclear wrinkling with perinuclear clearing) observed in the tumor (H\&E, $\times 100)$. (C) Scanning view of the portion with intraepithelial carcinoma without dermal invasion showing an area of full keratinocyte atypia, as evidenced by increased nuclear atypia, nuclear pleomorphism, and increased mitosis (H\&E, $\times 40)$. (D) Higher view of the full-thickness atypia, with more evident atypical mitotic figures and nuclear pleomorphism (H\&E, ×400). Courtesy of Dr. Alec Maquiling, Department of Laboratories, Philippine General Hospital, 2017.

erosexual practice. All patients admitted to having engaged in both insertive and receptive anal intercourse. All disclosed to engage in insertive more frequently than receptive anal intercourse.

\section{Treatment}

All underwent excision in prone jackknife position and allowed to heal by secondary intention. Total operative time has a median of 60 minutes (range, 45-90 minutes). None of these patients required blood transfusion during or after the operation. These patients' median postoperative length of stay was 2 days (range, 1-11 days).

\section{Outcomes and follow-up}

The median time to complete epithelialization was 4 weeks (range, 2-16 weeks). Two had recurrence of perianal warts between 2 and 3 months from time of surgery. These were addressed with repeat cauterization. No further recurrences have since been observed.

Four had an anal stricture. Of these, 3 underwent anal dilatation alone. No functional impairment was reported in these 3 patients. The 4th patient had to undergo a proximal bowel diversion. The definitive plan to perform an anoplasty has yet to be done, as the patient has been lost to follow up.

On histopathologic analysis, 1 patient was found to have intraepithelial carcinoma without dermal invasion within the BLT (Fig. 4). No adjuvant treatment was recommended after discussion in a multidisciplinary conference. Median follow-up of the patients were reported up to 8 months postoperatively (range, 1-24 months).

\section{DISCUSSION}

First described in 1925 by Buschke and Lowenstein, the giant condyloma acuminata or BLT is a slow-growing, locally aggressive verrucous lesion that is found in the ano-urogenital region [1]. It is an STI with an estimated incidence of $0.1 \%$ in the general adult population [2].

HPV, most commonly types 6 and 11, has been implicated as the etiologic factor and trigger for this condition [3]. The exact mechanism is yet to be elucidated; however, the rapid growth and malignant transformation of BLT is influenced by the host's immune response [3]. One hypothesis is that HPV invades the geni- 

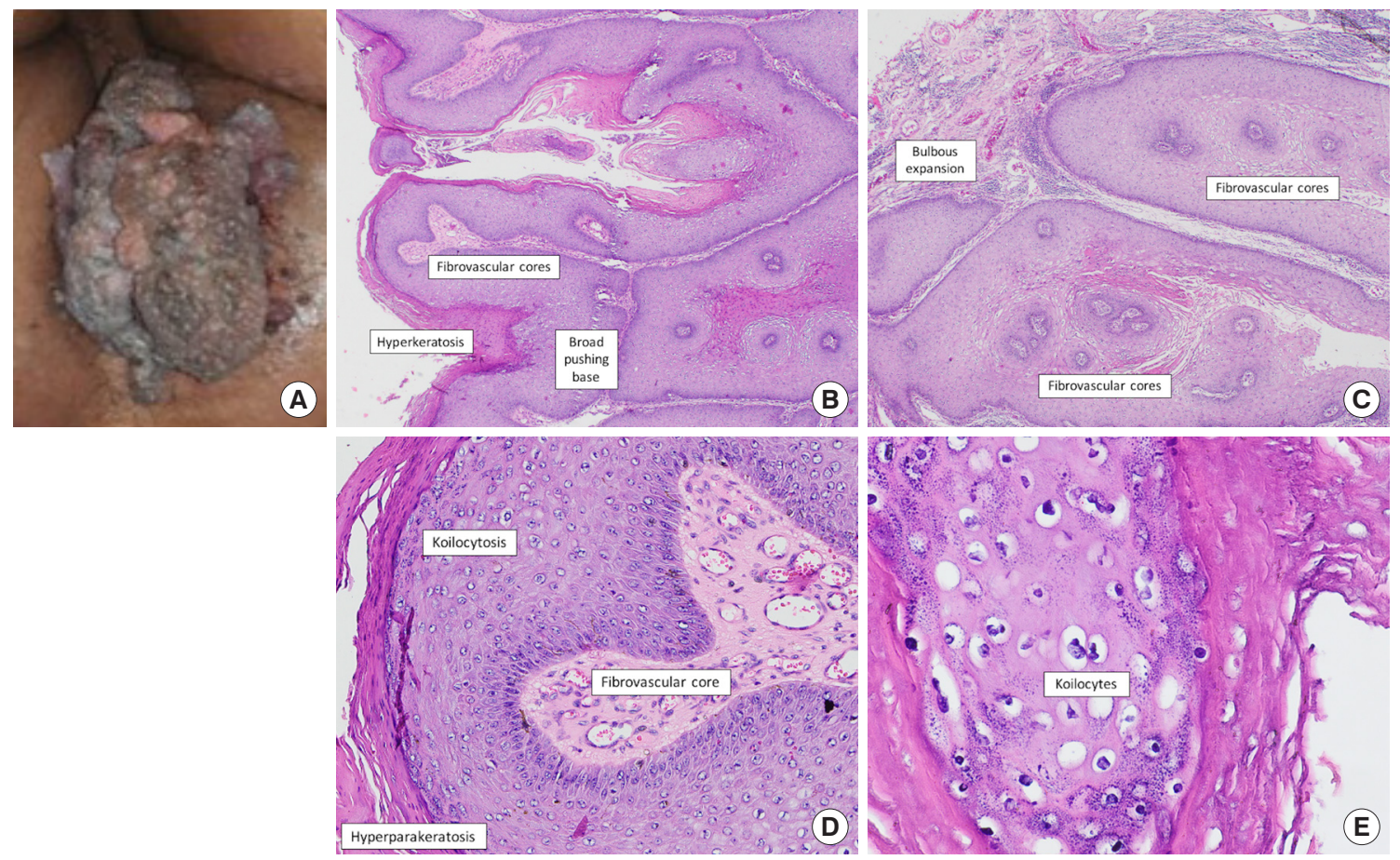

Fig. 5. Gross and histopathologic features of Buschke-Lowenstein tumor in a 29-year-old male. (A) Gross appearance of the fungating anal mass. (B) Scanning view of the tumor exhibiting hyperkeratosis (thickened cornified), papillae with prominent fibrovascular cores and broad pushing base $(\mathrm{H} \& \mathrm{E}, \times 40)$. (C) Another scanning view on other areas of the tumor which shows fibrovascular cores, broad pushing borders, and endophytic pattern of growth and more prominent bulbous expansion into underlying tissue (H\&E, $\times 40)$. (D) Low power view of the tumor showing a rich fibrovascular core, koilocytosis, and hyperparakeratosis (hyperkeratosis has retained nuclei in cornified layer) (H\&E, $\times 100$ ). (E) Higher magnification showing koilocytosis (proliferation of koilocytes which are superficial or intermediate squamous cells with large and irregular, well defined perinuclear halos with a cookie cutter border and cytoplasmic thickening) (H\&E, ×400). Courtesy of Dr. Ivana Ungajan, Department of Laboratories, Philippine General Hospital, 2019.

tal epidermal basal layer cells through microabrasions. The E7 gene of the virus impairs the antigen-presenting cells in the skin; hence, it stays undetected for extended periods of time. This eventually results in impairment of the host cells to induce telomerase resulting in the immortalization of the infected cells. The chronic oxidative stress within the HPV-infected cells results in increased susceptibility to DNA damage and eventually, malignant transformation [4].

It is more common among those in the 4th to 6th decade of life; however, a much younger population was seen in this study. Risk factors include immunosuppression, chronic irritation, and poor personal hygiene [5-7].

BLT initially presents as a keratotic plaque that eventually increases in size. In the perianal area, it typically grows from the mucocutaneous junction to the perianal area, with the anal canal often being spared [8]. It has a propensity for secondary infections, foul-smelling odor, and fistula formation.

Grossly it appears as a bulky tumor suggesting an aggressive behavior; however, on histopathology as shown in Fig. 5, it resembles condyloma acuminata with its benign appearance and negligible cellular atypia, but also has characteristics of thick stratum cor- neum, marked papillary proliferation, deep local invasion, and displacement of surrounding tissues $[3,6]$. This tumor has a low incidence of metastasis; however, it is reported that $50 \%$ of patients present with recurrence leading to a poorer prognosis $[2,6,9]$.

Malignant transformation has been reported in $30 \%$ to $56 \%$ of cases, with an average time of transformation of 5 years $[6,10$, 11]. In this study, 1 patient was found to have intraepithelial carcinoma without dermal invasion. This supports the hypothesis that condyloma acuminata and BLT might be within a contiguous but not obligatory precancerous spectrum, and that other factors like age, size of the mass, and recurrences do not correlate with histological diagnosis $[12,13]$.

Biopsy of the lesion to determine whether there is malignant transformation is not recommended as this will not provide a definitive histological feature; only complete excision of the lesions and histological examination are essential for the final pathological diagnosis [14].

Because it is a relatively rare condition, no standardized management approach has been established yet. Wide local excision remains to be the treatment of choice, as local control usually leads to good prognosis. Surgery has been reported to have a dis- 
ease-free status in $45.5 \%$ of patients $[15,16]$. Other treatment modalities include chemotherapy (systemic and intralesional), carbon dioxide laser therapy, and photodynamic therapy, although their effects have not yet been established. Radiation therapy alone is controversial because it could induce anaplastic transformation of the tumor. It is only used as a neoadjuvant treatment to decrease the size, or as a last resort for inoperable tumors [17].

In instances where malignant transformation has transpired, the optimal treatment has not yet been well defined. In a review of 11 patients treated with radical surgery, only 5 remained disease-free [11]. This has prompted some to recommend preoperative chemoradiotherapy with Nigro protocol to downstage extensive tumors, followed by radical surgery $[2,18]$. This protocol followed by surgery confers the advantage of permitting preservation of anorectal function, and improving survival and local control compared to surgery alone, as seen in a few reported cases [19].

Since BLT starts as small lesions that progress over several months to years, seeking timely medical attention may prevent potential growth into a locally advanced tumor. Close follow-up could also lead to better patient outcomes by allowing for timely intervention while recurrences remain small [20].

In conclusion, BLT is a rare STI characterized by local aggressiveness but with low malignant potential. Wide excision, either with concomitant grafting or healing by secondary intention, remains to be the mainstay of treatment. Multicenter studies are urgently needed to better understand the disease, its prognosis, and treatment.

\section{CONFLICT OF INTEREST}

No potential conflict of interest relevant to this article was reported.

\section{REFERENCES}

1. Loewenstein LW. Carcinoma-like condylomata acuminata of the penis. Med Clin N Am 1939;23:789-95.

2. Levy A, Lebbe C. Buschke-Löwenstein tumour: diagnosis and treatment. Ann Urol (Paris) 2006;40:175-8.

3. Ahsaini M, Tahiri Y, Tazi MF, Elammari J, Mellas S, Khallouk A, et al. Verrucous carcinoma arising in an extended giant condyloma acuminatum (Buschke-Löwenstein tumor): a case report and review of the literature. J Med Case Rep 2013;7:273.

4. Venter F, Heidari A, Viehweg M, Rivera M, Natarajan P, Cobos E. Giant condylomata acuminata of buschke-lowenstein associated with paraneoplastic hypercalcemia. J Investig Med High Impact Case Rep 2018;6:2324709618758348.

5. Boshart M, zur Hausen H. Human papillomaviruses in BuschkeLöwenstein tumors: physical state of the DNA and identification of a tandem duplication in the noncoding region of a human papillomavirus 6 subtype. J Virol 1986;58:963-6.
6. Creasman C, Haas PA, Fox TA Jr, Balazs M. Malignant transformation of anorectal giant condyloma acuminatum (BuschkeLoewenstein tumor). Dis Colon Rectum 1989;32:481-7.

7. Nash G, Allen W, Nash S. Atypical lesions of the anal mucosa in homosexual men. JAMA 1986;256:873-6.

8. Kauffman CL, Alexandrescu DT. Giant condylomata acuminata of Buschke and Lowenstein clinical presentation [Internet]. Medscape; 2018 [cited 2019 Dec 17]. Available from: https://emedicine.medscape.com/article/1132178-clinical\#b2.

9. Chao MW, Gibbs P. Squamous cell carcinoma arising in a giant condyloma acuminatum (Buschke-Lowenstein tumour). Asian J Surg 2005;28:238-40.

10. Chu QD, Vezeridis MP, Libbey NP, Wanebo HJ. Giant condyloma acuminatum (Buschke-Lowenstein tumor) of the anorectal and perianal regions. Analysis of 42 cases. Dis Colon Rectum 1994;37: 950-7.

11. Bertram P, Treutner KH, Rubben A, Hauptmann S, Schumpelick $\mathrm{V}$. Invasive squamous-cell carcinoma in giant anorectal condyloma (Buschke-Löwenstein tumor). Langenbecks Arch Chir 1995; 380:115-8.

12. Masih AS, Stoler MH, Farrow GM, Wooldridge TN, Johansson SL. Penile verrucous carcinoma: a clinicopathologic, human papillomavirus typing and flow cytometric analysis. Mod Pathol 1992;5:48-55.

13. Trombetta LJ, Place RJ. Giant condyloma acuminatum of the anorectum: trends in epidemiology and management: report of a case and review of the literature. Dis Colon Rectum 2001;44:1878-86.

14. Safi F, Bekdache O, Al-Salam S, Alashari M, Mazen T, El-Salhat H. Management of peri-anal giant condyloma acuminatum: a case report and literature review. Asian J Surg 2013;36:43-52.

15. Fukunaga M, Yokoi K, Miyazawa Y, Harada T, Ushigome S. Penile verrucous carcinoma with anaplastic transformation following radiotherapy. A case report with human papillomavirus typing and flow cytometric DNA studies. Am J Surg Pathol 1994;18:5015.

16. Klein N, Jasch K, Kimmritz J, Hermes B, Harth W. Operative therapy of a monstrous Buschke-Löwenstein tumor. Dermatology 2007;215:264-5.

17. Renzi A, Giordano P, Renzi G, Landolfi V, Del Genio A, Weiss EG. Buschke-Lowenstein tumor successful treatment by surgical excision alone: a case report. Surg Innov 2006;13:69-72.

18. Elliot MS, Werner ID, Immelman EJ, Harrison AC. Giant condyloma (Buschke-Loewenstein tumor) of the anorectum. Dis Colon Rectum 1979;22:497-500.

19. Shenoy S, Nittala M, Assaf Y. Anal carcinoma in giant anal condyloma, multidisciplinary approach necessary for optimal outcome: two case reports and review of literature. World J Gastrointest Oncol 2019;11:172-80.

20. Kim HG, Kesey JE, Griswold JA. Giant anorectal condyloma acuminatum of Buschke-Löwenstein presents difficult management decisions. J Surg Case Rep 2018;2018:rjy058. 